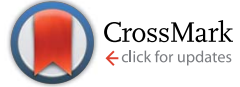

Cite this: RSC Adv., 2016, 6, 28388

Received 16th February 2016 Accepted 10th March 2016

DOI: $10.1039 / c 6 r a 04194 a$

www.rsc.org/advances

\section{Understanding the formation of aligned, linear arrays of Ag nanoparticles $\dagger$}

\author{
Roché M. Walliser, ${ }^{a}$ Rita Tóth, ${ }^{\text {b }}$ István Lagzi, ${ }^{c}$ Daniel Mathys, ${ }^{d}$ Laurent Marot, $^{e}$ \\ Artur Braun, ${ }^{\mathrm{b}}$ Catherine E. Housecroft ${ }^{\mathrm{a}}$ and Edwin C. Constable ${ }^{\mathrm{a}}$
}

\begin{abstract}
We report the self-assembly of aligned arrays of silver nanoparticles governed by a reaction-diffusion-precipitation process. The average $2 \mu \mathrm{m}$ wide bands containing nanoparticles which are $\sim 160 \mathrm{~nm}$ in diameter are highly periodic with $\sim 0.9-3 \mu \mathrm{m}$ spacing. Morphological and analytical characterization of the particles has provided crucial information for the formulation of a series of reactions explaining the band formation. We propose that the silver/silver oxide colloids in the bands turn into elemental silver particles upon UV illumination.
\end{abstract}

Self-assembly of small building blocks, such as nanoparticles and colloids, into highly ordered structures has gained much interest during the past years due to their unique chemical, optical, electronic and magnetic properties. ${ }^{1}$ Today, the biggest challenge in materials science is understanding and controlling the assembly of building blocks into nanostructured materials. ${ }^{2}$ These materials exhibit emergent properties that differ from those of bulk materials and the individual building blocks. Bottom-up approaches offer robust, efficient, upscalable and cheap methods to drive the assembly of the building blocks by regulating and controlling interactions between the elements. ${ }^{3}$

Liesegang phenomena, the self-assembly of small colloidal particles into macroscopic patterns in gelled media, are among the longest established examples of pattern formation in chemical systems. ${ }^{4}$ Precipitation reactions and counterdiffusion of two water soluble ions (called outer and inner electrolytes) in a gel in various conditions can give rise to

${ }^{a}$ Department of Chemistry, University of Basel, Basel, Switzerland

${ }^{b}$ Laboratory for High Performance Ceramics, Empa, Swiss Federal Laboratories for Materials Science and Technology, Dübendorf, Switzerland. E-mail: ritatoth1013@ gmail.com

${ }^{c}$ Department of Physics, Budapest University of Technology and Economics, P. O. Box H-1521, Budafoki út 8, Budapest, Hungary

${ }^{d}$ Centre of Microscopy, University of Basel, Basel, Switzerland

${ }^{e}$ Department of Physics, University of Basel, Basel, Switzerland

$\dagger$ Electronic supplementary information (ESI) available: Experimental methods, electron microscopy, XPS measurements data and annealing details. See DOI: 10.1039/c6ra04194a banded and quasi-periodic structures. ${ }^{5}$ These bands consist of collections of small nano- and microparticles. ${ }^{6,7}$ In the past decade, a number of efforts have been made to rescale this phenomenon from the macroscale to the microscale. ${ }^{7,8}$ Silver nanostructures are of high interest due to their unique optical, electrical and antibacterial properties. ${ }^{9}$

We now report the generation of a microscale pattern of silver nanoparticles utilizing diffusion and chemical transformation of silver ions to a metallic form in an alkaline environment. We propose two potential mechanisms for the formation of the self-assembled pattern based on morphological and analytical studies. ${ }^{\mathbf{1 0}}$

The pattern generation is initiated by a silver nitrate loaded agarose block (stamp) placed on the surface of a 4-5 $\mu$ m thick alkaline gelatin film containing aqueous $\mathrm{NH}_{3}$ (Fig. 1). The $\mathrm{AgNO}_{3}$ from the stamp diffuses into the film and aligned bands of nanoparticles form around the stamp (Fig. 1 and 2a). An average band height of $40-90 \mathrm{~nm}, \mathrm{FWHH}$ (full width at half height) of $2.0 \mu \mathrm{m}$ and spacings of $3.15 \mu \mathrm{m}$ were determined from SEM-FIB cross section images, made at approximately the

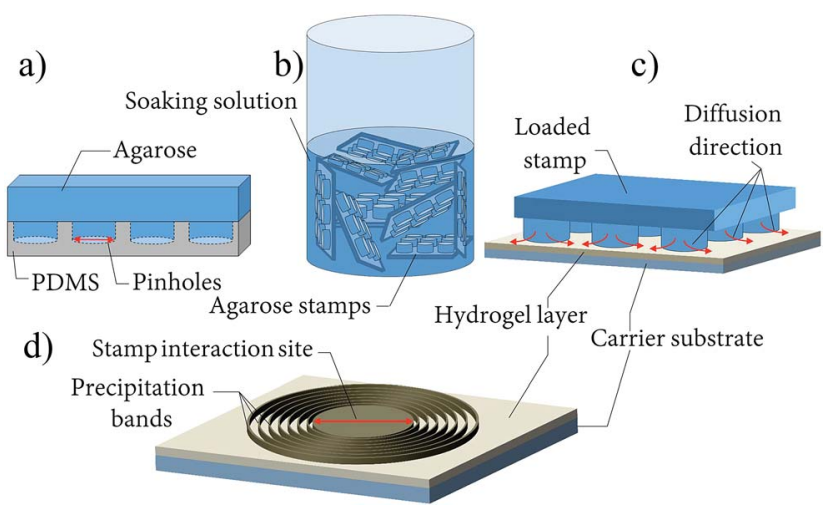

Fig. 1 (a) Agarose stamp is prepared in a PDMS mould (b) and soaked in silver nitrate solution ( $0.3 \mathrm{M}$ ). (c) Silver nitrate diffuses from the stamp into the alkaline hydrogel layer and (d) concentric precipitation bands form around the interaction site. 


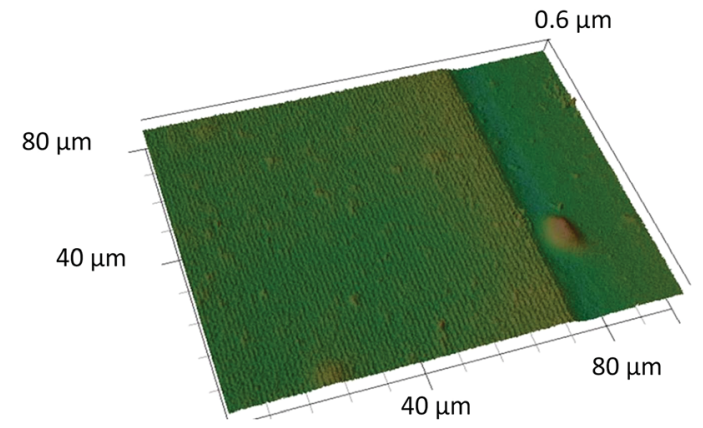

a)

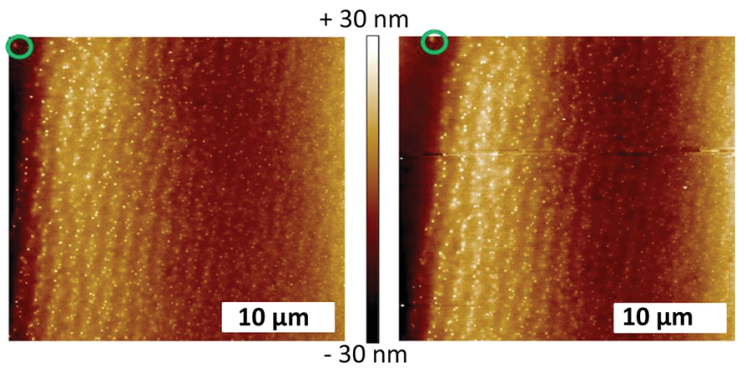

b)

Fig. 2 (a) 3D laser profile image at the end of the precipitation zone (the film was UV irradiated, $256 \mathrm{~nm}$ ). $10 \mathrm{w} / \mathrm{w} \%$ gelatin I film (see ESI $\uparrow$ ) containing $0.3 \mathrm{w} / \mathrm{w} \%$ ammonia spin coated with $300 \mathrm{rpm}, 90$ minutes stamping time. (b) AFM profiles before (left) and after (right) UV-irradiation $(256 \mathrm{~nm})$. The green marker in both images shows the same particle. Measurements were performed in contact mode $(30 \mu \mathrm{m} \times$ $30 \mu \mathrm{m})$.

same distance $(350 \mu \mathrm{m})$ from the stamp core. The diameter of the particles composing the bands is around $160-170 \mathrm{~nm}$ and slightly increases with increasing distance from the stamping center, similar to the classical Liesegang system. ${ }^{7}$

Illumination by UV light was necessary to visualize the highly periodic bands by optical microscopy, which raises the question as to whether the bands form before or during illumination. The gelatin film "buckles" at the bands containing the nanoparticles; therefore, the presence of the bands can be confirmed by atomic force microscopy (AFM) in contact mode. The AFM profile of a pattern prepared in a dark box was recorded in the dark. Thereafter, the film was irradiated $\left(\lambda_{\text {irr }}=256 \mathrm{~nm}\right)$ for 30 minutes and the AFM profile was re-recorded at the same place. Fig. $2 \mathrm{~b}$ clearly shows that the bands had formed prior to the light treatment. Superimposed AFM surface profiles also demonstrate that UV-irradiation has no influence on the shape/ structure of the bands.

To determine the chemical composition of the particles forming the periodic bands, electron microscopy images and energy dispersive X-ray spectroscopy (EDX) spectra were obtained. Individual particles in $\sim 90-150 \mathrm{~nm}$ thin microtome cuts (cross sections) of a band were analyzed by scanning transmission electron microscopy (STEM). The high intensities of the $\mathrm{Ag}$ peaks indicate that the material forming the particles contains silver (Fig. 3a). The same result was found using scanning electron microscopy (SEM-EDX) (Fig. 3b) and in focused ion beam cuts analyzed by SEM_FIB (Fig. 3c) (details in ESI, Fig. 1S, Tables $1 \mathrm{~S}$ and $2 \mathrm{~S} \dagger$ ). Fig. $3 \mathrm{~b}$ and $\mathrm{S} 2 \dagger$ also reveal that the particles
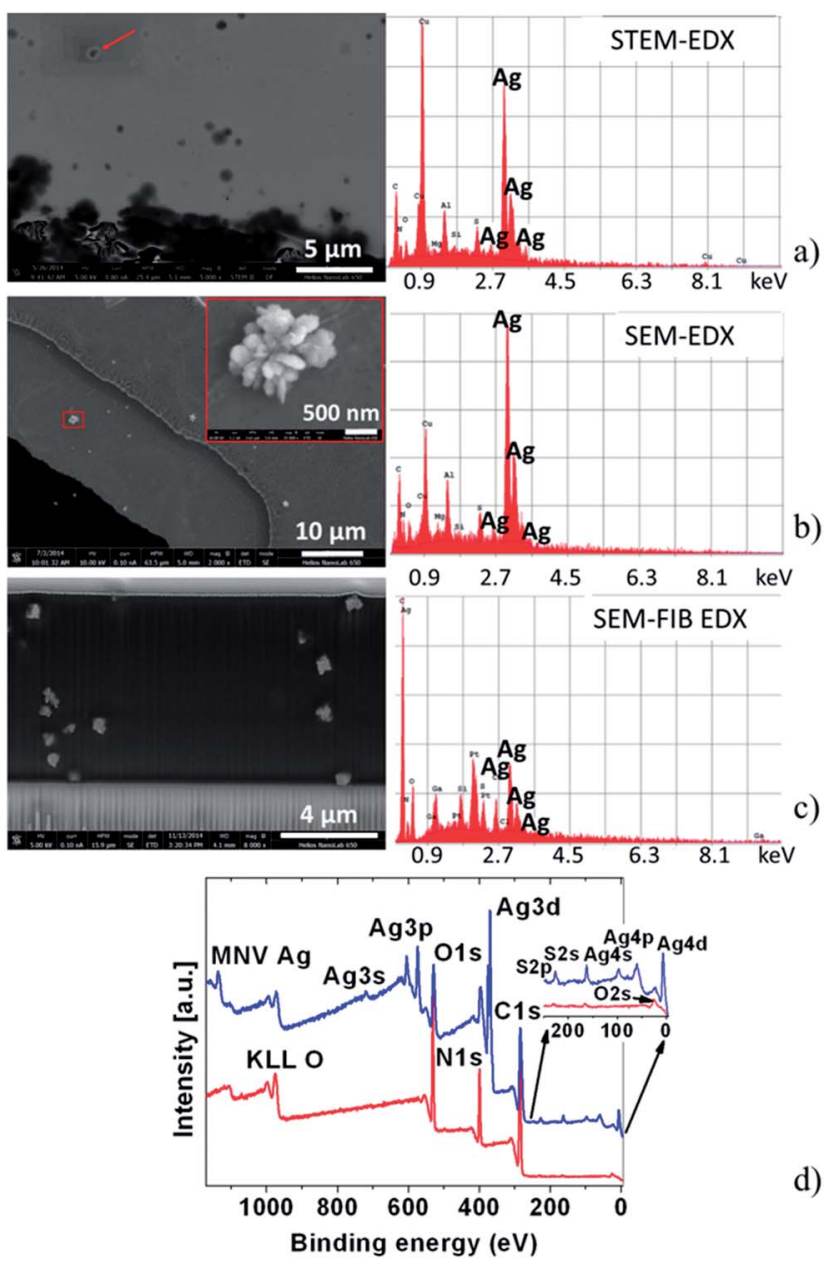

d)

Fig. 3 (a) STEM image of a microtome cut and EDX measured on the particle (red arrow) on the top left. (b) SEM image showing the morphology of the particles in a band and EDX spectrum of the particles. The red square indicates the location of the zoomed in image. (c) SEM-FIB image of the focused ion beam cross section cut and EDX spectrum of the particles forming bands and EDX spectrum of the particles. (d) Survey spectra registered by XPS for a gelatin film containing bands (blue) and a gelatin reference film (red). See spectra also in ESI.†

forming the bands are built from smaller nanoparticles. In addition, the SEM-FIB cross section images clearly show the nanoparticles forming well-developed and distinguishable bands both inside and on the surface of the gelatin layer.

To investigate the oxidation state of the silver species in the particles, X-ray photoelectron (XPS) measurements were performed on bands illuminated by UV light for 30 minutes (Fig. 3d and $\mathrm{S} 3 \uparrow)$. As the XPS spot size on the sample is $0.3 \times 0.3 \mathrm{~cm}^{2}$, electrons are recorded not only from the particles forming the few microns wide bands, but also from the material between the bands and from the gelatin film. Since charge correcting the spectra was impossible, the measured data revealed several oxidation states for silver, most probably a mixture of silver(I or II) oxide, metallic state $(\mathrm{Ag}(0))$ and $\mathrm{Ag}_{2} \mathrm{~S}^{1.14}$ This is in agreement with the optical observations and the collected EDX data (Fig. 3 and $\mathrm{S} 4 \dagger$ ). Since the XPS results were not conclusive, further 
analytical studies were performed to determine the chemical composition.

In aqueous solutions, solid silver(I) oxide is in equilibrium with solution phase $\left[\mathrm{Ag}(\mathrm{OH})_{2}\right]^{-}$anions which could react with aerial $\mathrm{CO}_{2}$ to form solid $\mathrm{Ag}_{2} \mathrm{CO}_{3}$ (ref. 15-20) which darkens when irradiated with UV light. ${ }^{21}$ However, the pattern also forms in a glove box under a $\mathrm{N}_{2}$ atmosphere, indicating that the primary particles are not composed of $\mathrm{Ag}_{2} \mathrm{CO}_{3}$ and also excludes the formation of $\mathrm{Ag}_{2} \mathrm{~S}$ from $\mathrm{Ag}(0)$ and aerial $\mathrm{H}_{2} \mathrm{~S} .{ }^{22}$ On the other hand, the bands get darker outside the inert atmosphere, therefore, the reaction forming $\mathrm{Ag}_{2} \mathrm{~S}$ from $\mathrm{Ag}(0)$ and aerial $\mathrm{H}_{2} \mathrm{~S}$ cannot be ruled out completely.

Silver nitrate reacts with ammonia forming a diammine-silver complex ${ }^{23}\left[\mathrm{Ag}\left(\mathrm{NH}_{3}\right)_{2}\right]^{+}$which is light sensitive and can be reduced to $\mathrm{Ag}(0)$ by irradiation. We tested ten alkaline solutions: diethylamine and triethylamine (each 0.1, 0.3 and $1.0 \mathrm{w} / \mathrm{w} \%$ ), and $\mathrm{KOH}$ or $\mathrm{NaOH}$ (each $0.01 \mathrm{M}$ and $0.1 \mathrm{M}$ ). In each case band formation was observed, and we therefore conclude that silver-diammine complexes do not have a critical role in band formation.

A system exhibiting silver-containing bands on the micro- to millimeter scale was recently published by Nabika et al. ${ }^{24}$ In their system, gelatin was used as the hydrogel and silver nitrate as the invading electrolyte, but in contrast to our system, the authors worked under acidic conditions and used sodium citrate as a reducing agent and methionine as an additive. They proposed that the process is governed by the formation of a silver methionine complex that has a different redox behavior than silver ions. To investigate the potential role of methionine in our system, we used different types of gelatins as well as other hydrogels as mediums for band formation. Eight different kinds of gelatins were tested (see ESI $\dagger$ ). Only alkaline gelatin films showed band formation; in neutral and acidic gelatin films the precipitate did not form a pattern. Agarose, agar-agar, polyethylene-glycol and polyvinyl-alcohol (PVA) ${ }^{25,26}$ films were also tested with and without additional methionine ( 0.1 and $0.5 \mathrm{w} / \mathrm{w} \%$ ). Liesegang band formation was observed in alkaline agarose and PVA films. The base used had no influence; the only critical point was a pH above 7.2. Interestingly, methionine did not enhance the band formation in gelatin or any other tested hydrogel system. Therefore, silver-sulfur intermediates, which may form in gelatin or other hydrogel solution, do not have a role in band formation under alkaline conditions.

Based on the results of the hydrogel studies and the material composition analysis, we propose a series of reactions which could lead to pattern formation (eqn (1)-(4)):

$$
\begin{gathered}
\mathrm{Ag}^{+}(\mathrm{aq})+2 \mathrm{OH}^{-} \rightarrow\left[\mathrm{Ag}(\mathrm{OH})_{2}\right]^{-}(\mathrm{aq}) \\
\mathrm{Ag}^{+}(\mathrm{aq})+\left[\mathrm{Ag}(\mathrm{OH})_{2}\right]^{-}(\mathrm{aq}) \rightarrow \mathrm{Ag}_{2} \mathrm{O}(\mathrm{s})+\mathrm{H}_{2} \mathrm{O} \\
{\left[\mathrm{Ag}(\mathrm{OH})_{2}\right]^{-}(\mathrm{aq}) \stackrel{\text { hydrogel }(\mathrm{H})}{\longrightarrow} \mathrm{Ag}^{0}(\mathrm{~s})+\text { oxidised } \mathrm{H}} \\
2 \mathrm{Ag}_{2} \mathrm{O}(\mathrm{s}) \stackrel{h v}{\longrightarrow} 4 \mathrm{Ag}^{0}(\mathrm{~s})+\mathrm{O}_{2}(\mathrm{~g})
\end{gathered}
$$

In alkaline aqueous and hydrogel solutions of $\mathrm{AgNO}_{3}$, $\left[\mathrm{Ag}(\mathrm{OH})_{2}\right]^{-}$ions form (eqn (1)) which are unstable and either react with $\mathrm{Ag}^{+}$ion and produce silver(I) oxide (eqn (2)) or are reduced in the presence of a reducing agent such as the hydrogel to elemental silver (eqn (3)). ${ }^{21,27-31}$ As most silver compounds, silver(I) oxide is photosensitive and decomposes into elemental silver when exposed to direct sun or UV light (eqn (4)). It is known from our AFM study that bands are formed but are not visible before irradiation with light.

A first model is that the material forming the particles in the bands is $\mathrm{Ag}_{2} \mathrm{O}$ (stabilized by the gelatin matrix), which is reduced to elemental silver on the surface of the particles upon illumination. This proposal is supported by the XPS results which show the presence of both $\mathrm{Ag}(0)$ and $\mathrm{Ag}_{2} \mathrm{O}$ in the bands. However, no change in the morphology of the bands was observed by AFM after illumination implying that the reduction to elemental silver results in no significant change that can be detected by AFM. It is known that $\mathrm{Ag}_{2} \mathrm{O}$ dissolves in ammonia. Freshly prepared bands, illuminated for 30 minutes, were treated with a $3 \mathrm{w} / \mathrm{w} \%$ aqueous ammonia solution and the bands disappeared while the gelatin hydrogel remained stable. If the films were illuminated for longer period of time ( 48 hours), the bands remained stable in aqueous $3 \mathrm{w} / \mathrm{w} \%$ ammonia solution. Nonetheless, these bands disappeared when treated with aqueous nitric acid solution which dissolves elemental silver. This suggests that during long irradiation, the initial $\mathrm{Ag}(\mathrm{I})$ oxide particles are reduced to $\mathrm{Ag}(0)$ completely, as opposed to only in a thin layer on the surface of the particles during short illumination.

An alternative route is based on the reducing and capping ability of gelatin (as well as PVA and agarose) resulting in elemental silver as the 'latent' bands. ${ }^{31,32}$ In other words, silver nanoparticles form directly in the hydrogel films and are stabilized in the hydrogel matrix. ${ }^{27,30-32}$ Silver nanoparticles can easily be oxidized by air and in our open system the surface of the nanoparticles would be covered with a thin layer of $\operatorname{Ag}(\mathrm{I})$ oxide $^{33-35}$ and $\mathrm{Ag}_{2} \mathrm{~S}$. This explains the presence of $\mathrm{Ag}(0), \mathrm{Ag}(\mathrm{I})$ oxide and $\mathrm{Ag}_{2} \mathrm{~S}$ in the XPS spectra. The darkening during UV illumination can simply be caused by a photographic effect: the $\mathrm{Ag}^{+}$ions present in the hydrogel and bands are reduced to silver while absorbing photoelectrons. ${ }^{36,37}$ The formed silver atoms are not stable, they can easily decompose to $\mathrm{Ag}^{+}$ions and free electrons. However, the silver nanoparticles in the Liesegang bands can serve as nucleation sites for photoelectron induced reduction of the $\mathrm{Ag}^{+}$ions. This is in agreement with the observation that only the bands darken during illumination, while the areas between the bands remain unchanged. As the silver nanoparticle color changes with the size, i.e. the initial yellow color darkens to brown and eventually turns to black, the bands become visible upon illumination. The change in the size is not detectable by AFM, since the darkening starts at approximately 10-20 nm particle size.

For a conclusive determination of the composition of the bands, additional information about the oxidation states of the particles in the bands before and after illumination would be needed. However, to the best of our knowledge there is no such high resolution method available which could detect the change of the silver oxidation state in the nanoparticles in the bands. A potential high resolution method would be scanning 
transmission X-ray microscopy; however, the broad absorption over the silver energy range also includes the nitrogen $\mathrm{K}$ edge, which causes significant interference due to nitrogen present in the gelatin, the membranes supporting the samples and the focusing optic of the instrument. In XPS measurements the resolution is too low to distinguish between the bands and the areas between bands, and in all analytical methods (STEM, SEM, FIB, EDX or XPS) except AFM, a radiation source is used, which - as seen in Video $\mathrm{S} 1 \dagger$ - can influence and change the structure of the particles. FIB-SEM studies enabled us to observe cross sections of the Liesegang bands and reveal that the main part of the band is inside the hydrogel matrix. The "buckle" of the hydrogel film that is observed with microscopy (Fig. 2a and $3 c$ ) is only the tip of the band.

In summary, we show a novel, inexpensive and simple method to create a highly periodic, silver nanoparticle pattern. FIB-SEM studies demonstrate that the bands are composed of $\approx 160 \mathrm{~nm}$ diameter nanoparticles inside and on the surface of the gelatin film. Systematic analysis of the composition led us to two possible mechanisms for the formation of the bands starting from $\mathrm{Ag}_{2} \mathrm{O}$ or $\mathrm{Ag}$ colloid particles. Subsequent thermal treatment at $360{ }^{\circ} \mathrm{C}$ removes the gelatine, turns any remaining $\mathrm{Ag}_{2} \mathrm{O}$ to $\mathrm{Ag}$ and binds the silver particles to a conducting substrate, while the pattern is fully preserved. We believe this flexible and easily adaptable method will open up new possibilities for the preparation of meso- and nanoscale periodic silver structures for applications which include nonlinear optical components, antibacterial medical components, and transparent conducting grids on electrodes.

\section{Acknowledgements}

Financial support for R. M. W. by the Swiss National Science Foundation under project no. SNF 200021-137868, for R. T. by the Marie Heim-Vögtlin Program under project no. PMPDP2139698 and for I. L. by the Hungarian Research Fund (OTKA K104666) is gratefully acknowledged.

\section{Notes and references}

1 (a) F. E. Kruisa, H. Fissana and A. Peleda, J. Aerosol Sci., 1998, 29, 511-535; (b) S. Eustis and M. A. El-Sayed, Chem. Soc. Rev., 2006, 35, 209-217; (c) P. K. Jain, X. Huang, I. H. El-Sayed and M. A. El-Sayed, Plasmonics, 2007, 2, 107-118.

2 (a) M. Li, H. Schnablegger and S. Mann, Nature, 1999, 402, 393-395; (b) K. J. M. Bishop, C. E. Wilmer, S. Soh and B. A. Grzybowski, Small, 2009, 5, 1600-1630; (c) M. Grzelczak, J. Vermant, E. M. Furst and L. M. LizMarzán, ACS Nano, 2010, 4, 3591-3605.

3 A. Biswas, I. S. Bayer, A. S. Biris, T. Wang, E. Dervishi and A. Faupel, Adv. Colloid Interface Sci., 2012, 170, 2-27.

4 R. E. Liesegang, Naturwiss. Wochenschr., 1896, 11, 353-362.

5 (a) G. Venzl and J. Ross, J. Chem. Phys., 1982, 77, 1302-1307; (b) S. C. Muller and J. Ross, J. Phys. Chem. A, 2003, 107, 79978008; (c) I. Lagzi, Langmuir, 2012, 28, 3350-3354.

6 (a) M. Al-Ghoul and T. Ghaddar, J. Nano Res., 2010, 11, 19-24; (b) M. Al-Ghoul, T. Ghaddar and T. Moukalled, J. Phys. Chem.
$B$, 2009, 113, 11594-11603; (c) V. I. Kuz'min, A. F. Gadzaov, D. L. Tytik, V. V. Vysotskii, S. A. Busev and A. A. Revina, Colloid J., 2014, 76, 439-446.

7 R. M. Walliser, F. Boudoire, E. Orosz, R. Tóth, A. Braun, E. C. Constable, Z. Rácz and I. Lagzi, Langmuir, 2015, 31, 1828-1834.

8 (a) I. T. Bensemann, M. Fialkowski and B. A. Grzybowski, J. Phys. Chem. B, 2005, 109, 2774-2778; (b) B. A. Grzybowski, K. J. M. Bishop, C. J. Campbell, M. Fialkowski and S. K. Smoukov, Soft Matter, 2005, 1, 114-128; (c) I. Lagzi, K. Bartlomiej and B. A. Grzybowski, J. Am. Chem. Soc., 2010, 132, 58-58.

9 (a) C. Kumar, Metallic Nanomaterials, Wiley, Weinheim, 2009, vol. 1; (b) K. M. M. Abou El-Nour, A. Eftaiha, A. AlWarthan and R. A. A. Ammar, Arabian J. Chem., 2010, 3, 135-140.

10 R. M. Walliser, PhD thesis, University of Basel, Faculty of Science, 2015, http://edoc.unibas.ch/view/creators/ Walliser=3ARoch=E9_M=2E $=3 \mathrm{~A}=3 \mathrm{~A} . \mathrm{html}$.

11 M. F. J. Al-Kuhaili, J. Phys. D: Appl. Phys., 2007, 40, 28472853.

12 A. N. Buckle and R. Woods, Colloids Surf., A, 1995, 104, 295305.

13 I. Lopez-Salido, D. C. Lim and Y. D. Kim, Surf. Sci., 2005, 588, 6-18.

14 I. Aruna, B. R. Mehta, L. K. Malhotra and S. M. Shivaprasad, J. Appl. Phys., 2008, 104, 064308.

15 C. Alonso, R. Salvarezza, J. Vara and A. Arvia, Electrochim. Acta, 1990, 35, 489-496.

16 P. A. Barnes, M. F. O'Connor and F. S. Stone, J. Chem. Soc. A, 1971, 3395-3398.

17 N. G. Keats and P. H. Scaife, Talanta, 1966, 13, 156-158.

18 T. A. Lowe, J. Hedberg, M. Lundin, S. Wold and I. O. Wallinder, Int. J. Electrochem. Sci., 2013, 8, 3851-3865.

19 P. Norby, R. Dinnebier and A. N. Fitch, Inorg. Chem., 2002, 41, 3628-3637.

20 W. J. Culbertson, Technical Report, Chemical Division Laboratory of Denver Research Institute, University of Denver, 1964.

21 P. Zanowiak, in Ullmann's Encyclopedia of Industrial Chemistry, John Wiley and Sons, Inc., 2014, vol. 33, p. 16.

22 L. Volpe and P. J. Peterson, Corros. Sci., 1989, 29, 1179-1196.

23 K. Oshitna and B. Tollens, Ber. Dtsch. Chem. Ges., 1901, 34, 1425.

24 H. Nabika, M. Sato and K. Unoura, Langmuir, 2014, 30, 50475051.

25 P. Hantz, Phys. Chem. Chem. Phys., 2002, 4, 1262-1267.

26 P. Hantz, J. Phys. Chem. B, 2000, 104, 4266-4272.

27 B. Ajitha and P. S. Reddy, Int. J. ChemTech Res., 2014, 6, 21232125.

28 C. E. Housecroft and A. G. Sharpe, Inorganic chemistry, 4th edn, 2012, p. 837.

29 A. Hollemann and N. Wiberg, Lehrbuch der Anorganischen Chemie, de Gruyter, New York, 102nd edn, 2008.

30 S. K. Mehta, S. Chaudhary and M. Gradzielski, J. Colloid Interface Sci., 2010, 343, 447-453. 
31 M. Darroudi, M. Bin Ahmad, A. H. Abdullah and N. A. Ibrahim, Int. J. Nanomed., 2011, 6, 569-574.

32 J. Pulit and M. Banach, Digest Journal of Nanomaterials and Biostructures, 2013, 8, 787-795.

33 L. A. Peyser, A. E. Vinson, A. P. Bartko and R. M. Dickson, Science, 2001, 291, 103-106.

34 O. A. D. Gallardo, R. Moiraghi, M. A. Macchione, J. A. Godoy, M. A. Pérez, E. A. Coronado and V. A. Macagno, $R S C A d v$., 2012, 2, 2923-2929.
35 J. C. Flores, D. Crespo, V. Torres, J. Carmona, W. M. Rainforth, Z. Zhou and J. M. Calderon-Moreno, J. Nanosci. Nanotechnol., 2012, 12, 8158-8164.

36 S. A. Cotton, Chemistry of precious metals, Blackie Academic \& Professional, London, 1997.

37 N. N. Greenwood and A. Earnshaw, Chemistry of the elements, Elsevier Ltd, 1984, p. 19. 